\title{
Narrativas de um cenário: ciclo de formação humana no município de Irecê - Bahia
}

\author{
Narratives of a scenario: cycle of human formation in the municipality \\ of Irecê - Bahia
}

\section{Narraciones de un escenario: ciclo de formación humana en el municipio de Irecê - Bahia}

\section{Maria Inez Carualho'}

Universidade Federal da Bahia, Faculdade de Educação, Professora Titular. https://orcid.org/0000-0002-8032-072X

Fabrízia Pires de Oliveira²

Rede de Educação Municipal de Irecê, Coordenadora Pedagógica. https://orcid.org/0000-0002-2214-1838

Resumo: Este texto, com discurso que se aproxima ecleticamente dos estudos curriculares filosoficamente não-finalistas e não-totalizantes, narra o cenário engendrado tempo espacialmente no semiárido brasileiro do século XXI, de implantação da Política de Ciclo de Formação Humana no município de Irecê, Bahia. É uma narrativa que, valendo-se de um encadeamento discursivo atravessador das seguintes dimensões: a. teórica - o movimento não essencialista e não fundacional e, b. geo-histórica - a longa parceria entre uma universidade brasileira e a Secretaria de Educação municipal, inventa (no sentido semântico de "trazer à luz" o que já existe) um singular cenário educativo. Informa que a cidade ofereceu Licenciatura em Pedagogia, Especialização em Currículo Escolar e Mestrado Profissional em Educação aos professores do município que em seus estudos acadêmicos elaboraram o que foi a base da Proposta Curricular hoje implantada no município: Ciclo de Educação Humana - Educação Integral e Integrada. Anuncia ser um cenário curricular possibilitador de uma leitura radical das coisas do mundo para os educadores - com potente formação docente - para os estudantes - com ciência e arte, principalmente, a literatura - e para o entorno do município que recebe as ressonâncias, mais ou menos diretamente, de tudo o que é realizado. E, finalizando, pondera que a aceitação da contingência, do risco, da provisoriedade, enfim, a emergência acontecimental encarada como parte compulsória da vida e, não como condição a ser combatida em nome do sucesso curricular, como ocorre, hegemonicamente nas propostas curriculares centralizadas, torna este cenário potencial traidor da natureza da BNCC.

Palavras-chave: Currículo. Fundamentos Fracos. Cenários Educativos. Ciclo de Formação Humana.

Pós-doutora em Desenvolvimento Curricular pela Universidade do Minho, Portugal; Doutorado e Mestre em Educação pelo Programa de Pós-Graduação em Educação da Universidade Federal da Bahia.

2 Doutora e Mestre em Educação pela Universidade Federal da Bahia. 
Abstract: This text, with a discourse that eclectically approaches philosophically non-finalist and nontotalizing curricular studies, narrates the scenario engendered in a space-time: the 21st century Brazilian semiarid, of implementation of the Human Training Cycle Policy in Irecê, Bahia. It is a narrative that, using a discursive chain that crosses the following dimensions: $a$. theoretical - the non-essentialist and nonfoundational movement, and b. geo-historical - the long partnership between a Brazilian university and the school district - invents (in the semantic sense of bringing to light what already exists) a unique educational scenario. Informs that the city offered a Degree in Pedagogy, Specialization in School Curriculum and Professional Master in Education to teachers in the municipality who, in their academic studies, developed the basis of the Curriculum Proposal today implemented in the municipality: Human Education Cycle - Integral and Integrated Education. It announces that it is a curricular scenario that makes possible a radical reading of the things of the world for educators - with a strong teacher education - for students - with science and art, especially literature - and for the surroundings of the municipality that receives resonances, more or less directly, of everything that is accomplished. And, in conclusion, he considers that the acceptance of contingency, risk, provisionality, in short, the evental emergency seen as a compulsory part of life and not as a condition to be fought in the name of curricular success, as it occurs, hegemonically, in the proposals centralized curriculum, makes this scenario a potential traitor to the nature of BNCC.

Keywords: Curriculum. Weak Fundamentals. Educational Scenarios. Human Formation Cycle.

Resumen: Este texto, con un discurso que se aproxima eclécticamente de los estudios curriculares filosóficamente no finalistas y no totalizadores, relata el escenario engendrado tiempo espacialmente en el semiárido baiano del siglo XXI, de la implementación de la Política del Ciclo de formación humana en el municipio de Irecê, Bahia. Es una narrativa que, utilizando un encadenamiento discursivo atravesador de las siguientes dimensiones: lo teórico - el movimiento no esencialista y no fundacional y, geo histórico - una larga asociación Secretaría de Educación - universidad, inventa len sentido semántico de sacar a la luz lo que ya existe) un entorno educativo único. Informa que la ciudad ofreció una Licenciatura en Pedagogía, Especialización en Currículo Escolar y Maestría Profesional en Educación a maestros en el municipio que en sus estudios académicos elaboraron de la base de la Propuesta Curricular implementada actualmente en el municipio: Ciclo de Educación Humana - Educación Integral e Integrada. Anuncia ser un escenario curricular que permite una lectura radical de las cosas del mundo para los educadores, con una potente formación docente, para los estudiantes, con ciencia y arte, principalmente literatura, y para el entorno que recibe resonancias, más o menos directamente, de todo que se realiza. Y finalmente, pondera sobre la aceptación de la contingencia, el riesgo, la provisionalidad, finalmente, la eventual emergencia acontecimental encarada como una parte obligatoria de la vida, y no como una condición a ser combatida en nombre del éxito curricular, como sucede, hegemónicamente, en propuestas curriculares centralizadas convierte este escenario traicionero potencial de la naturaleza del BNCC.

Palabras clave: Currículum. Fundamentos débiles. Escenarios educativos. Ciclo de formación humana.

Recebido em 9 de novembro de 2020 Aceito em 11 de fevereiro de 2021 


\section{INTRODUÇÃO}

Este texto - presente neste momento geo-histórico em que uma suposta crise educacional brasileira é hiperanunciada e que a urgência para a solução pauta centralidades e fundamentos fortes - tem a intenção de possibilitar ressonâncias plurais que borrando, traduzindo, deslocando o mundo das ideias desmanche os locais, pois os currículos são compulsoriamente localizados e singulares.

Aqui é narrada a invenção (no sentido semântico de trazer à luz o que já existe) de um cenário educacional contemporâneo em um lugar do semiárido brasileiro: o Município de Irecê. Uma invenção - a implantação do Ciclo de Formação Humana no Município de Irecê - Bahia - que singularizando o fazer currículo, foi a-com-tecendo com fenomenais deslocamentos. Quem diria, vivendo ao largo do mar, que tempo bom é quando chovel?

0 Ciclo de Formação Humana que a-com-tece hoje nas escolas da Rede de Educação Municipal é ressonância de antiga parceria educacional de Irecê com a Universidade Federal da Bahia conhecida como Projeto Irecê.

A estruturação da narrativa foi inventada com o apoio da(s) metáfora(s) presentes no clássico Heideggeriano $A$ origem da obra de arte: o conflito entre a Terra (matéria) e o Mundo (sentido). 0 Mundo existe a partir da Terra e a Terra só pode ser Terra no Mundo, dentro de um sistema. Mundo e Terra se relacionam entre si. Desse relacionamento incessante, tem-se um combate entre o mundo que não é o objeto visibilizado, mas tudo que está nele (ideia, sentido, expressão, impressão, matéria, forma, cor, significado, representação) e a Terra que é matéria-meio para uma forma de expressão, comunicação. Portanto, os termos Mundo e Terra, e o conflito entre eles, estão aqui presentes - com uma atribuição de sentido possibilitada por uma específica leitura da Origem da Obra de arte - como arcabouço metafórico que compõe o quadro do cenário curricular - em suas dimensões: descritivas da realidade, prescritivas do agir e concretas objetivações - aqui narrado.

Chegou-se assim, a três sessões: a. 0 mundo das ideias em suas virtualidades; b. A terra e seus a-com-teceres com dois subitens: 1. 0 Ciclo de Formação Humana: o atual cenário da Educação no município de Irecê, 2. 0 projeto Irecê: a longa e potente parceria município/universidade e, finalizando, c. Conflito mundo/terra: os dilemas postos e o pensar um cenário prospectivo. 


\section{MUNDO DAS IDEIAS EM SUAS UIRTUALIDADES}

A pretensão desta sessão é apresentar o mundo do cenário da Educação do município de Irecê. Mundo aqui, como já declarado, entendido como objeto não visibilizado onde estão contidos ideia, sentido, expressão, impressão, matéria, forma, cor significado, representação. Este mundo é forjado em um processo de desconstrução, um embasamento teórico que foi sendo inventado no processo e é, ao mesmo tempo, inventor deste cenário. Um discurso ecleticamente aproximado aos estudos curriculares filosoficamente nãofinalistas e não-totalizantes e que, ratificando uma proposição foucaultiana, localiza-se contemporaneamente como decidido habitante do espaço:

\footnotetext{
Estamos num momento, cremos eu, em que nossa experiência do mundo é menos a de uma vida longa que se desenvolve através do tempo, do que a de uma rede que liga pontos e faz intersecções com sua própria trama. Poder-se-ia dizer, talvez, que alguns conflitos ideológicos que animam a polêmica atual opõem os fiéis descendentes do tempo aos decididos habitantes do espaço. (FOUCAULT, 1980, p. 22, grifo nosso, tradução livre).
}

Um discurso operado e pensado por chaves que passam pelos pós (crítico, estruturalista, fundacionalista, moderno), pela fenomenologia e por metáforas traduzidas das ciências chamadas exatas. Encerra um caráter hibrido, no sentido em que carrega em si vestígios de diferentes abordagens epistemológicas e/ou ontológicas, contém uma reativação do próprio significante "hibrido", e sendo a expressão finita de nossas decisões, apresenta-se como tradução compulsoriamente infiel aos textos originais.

Estudos que engendraram o termo Pedagogia do A-com-tecer (CARVALHO, 2008, 2016; GRUPO FEP, 2019; CARVALHO; MOREIRA, 2018; JESUS, 2012): um modo de pensar/afirmar como o mundo funciona, se inventa e é inventado, ou melhor, como a-com-tece. $0 \mathrm{a}^{-} \mathrm{com}^{-}$ tecer; inventado na e para a Pedagogia do A-com-tecer é embasado na semântica da palavra - tecer junto. Um junto em que ao elemento humano se unem as naturezas naturais e artificiais (técnicas).

Sendo o movimento - forjador das manifestaç̃̃es - uma constante universal, o a-com-tecer é (seria) uma manifestação ordinária e compulsória. 0 a-com-tecer tece eventos. A pedagogia do A-com-tecer é, portanto, algo que contempla a cotidianidade com suas manifestações que são mais ou menos rotineiras ou ritualísticas (SOUZA, 2003).

0 movimento do A-com-tecer, sendo ele acontecimento (ŽlŽEK, 2017) ou não, ritual ou rotina, resulta em eventos, ou seja, o movimento (a-com-tecer) leva ao fato (evento). Por definição, os eventos são únicos, não se repetem; seriam, portanto, elementos de atualidade. 
Por isso, a cada novo a-com-tecer as coisas preexistentes mudam o seu conteúdo e também mudam sua significação (SANTOS, 1996). Um entendimento de mundo que deseje levar em conta os eventos obriga-se, também, a diferenciá-los. Tudo passando pela linguagem.

Diferenciá-los leva às visibilidades (materializações) que chamamos de Cenário. Antever o mundo como cenário alcança os pesquisadores no campo da alta energia onde não há mais conceitos opositores e, sim, um complexo cenário relacional, engendrado a partir de relações ecológicas entendidas como relações entre as naturezas de todas as coisas. Nesse sentido, tudo contido nos cenários - desde os elementos mais naturais aos mais artificializados - é estruturante, nada é mera ilustração. Compreender os cenários, marca da pedagogia do a-com-tecer, é possível com radical leitura dos mais variados textos que se apresentam sobre e em cada cenário e seus jogos discursivos.

Neste sentido, os caminhos/desvios dos currículos escolares, sejam como estudo descritivo da realidade e/ou prescritivos do agir e em suas concretas objetivações são singulares, provisórios, contingentes, híbridos, caleidoscópicos, pois densa e intensamente marcados pelo tempo/espaço presente das produções/ações. A concretude de cada cenário não é um conjunto de chapéus dispostos organizadamente em uma estilizada chapeleira, mas chapéus perdidos na lama dos a-com-teceres, que tanto aduba como destrói.

Não é uma abordagem humanista, pois descentraliza o humano; nem moralista, pois não é proposta de encontrar o melhor modo de a-com-tecer, enfim, acredita-se que não há controle pleno do que a-com-tece.

A invenção deste conjunto teórico é uma cascata de atualizações (LEVY, 1996) que engloba as aproximações - quiçá, sem muitas contradições - entre a fenomenologia heideggeriana (2006), com a potente teorização do conflito entre Mundo e Terra; a indeterminação/caos de llia Prigogine (1996) com o jogo de atualização/possibilidades; a complexidade de Merrel (1997), ao conceituar Ponto Cinza; o pós-modernismo de Vattimo (2007), notadamente, nas propostas de fraco fundamento; o anarquismo de Feyerabend (1989) com a postulação tudo vale, mas não vale tudo; a teorização radical das disputas linguísticas de Lopes (2013) e Macedo (2013); o pós-estruturalismo livre de Derrida (1999, 2005); o pósfundacional através de Gabriel (2016); o pós-qualitativo de St. Pierre (2018), e Roland Barthes (2007) que ao nos alertar sobre a possibilidade de trapacear da língua, nos possibilitou a criação de um currículo trapaceiro e Deleuze que ao apontar que não existe obra de arte que não faça apelo a um povo que ainda não existe (DELEUZE, 1999, p. 14) nos desperta para entender que o currículo como resistência artística, é apelo a um povo que ainda não existe.

Tudo isto instituidamente declarado, conhecido por muitos dos autores sociais da Educação de lrecê, apropriados por alguns, aceito por outros e transitando caleidoscopicamente 
junto às outras abordagens mais iluministas, teleológicas, conservadoras que, como parte do instituinte, também, estão presentes na configuração/constituição do cenário em estudo: Ciclo de Formação Humana no Município de Irecê - Bahia.

\section{A TERRA E SEUS A-COM-TECERES}

A pretensão desta sessão é apresentar nossa Terra. Optou-se por uma narração descritiva dos cenários que emergiram no território educacional de Irecê. Iniciamos pelo cenário atual com uma descrição pautada no que está, hoje, instituído. Leitura atenta dessas duas sessões iniciais, levará a percepção que, como defendido no mundo das ideias, o local, de fato, desmanchou o mundo. Após desta descrição do momento atual, na segunda parte desta sessão, uma narrativa outra se impôs e a sessão é concluída com a descrição dos movimentos ligados ao Projeto Irecê que antecederam a emergência dos Ciclos de Formação Humana.

\subsection{O CICLO DE FORMAÇÃO HUMANA: O ATUAL CENÁRIO DA EDUCAÇÃO NO MUNICÍPIO DE IRECÊ}

Para a narração descritiva do cenário posto, seguem trechos do Referencial Curricular por Ciclo de Formação Humana para a Rede Municipal em estudo (IRECÊ, 2020):

A Proposta Curricular por Ciclo de Formação Humana, identificada a seguir como $\mathrm{CFH}$, foi formulada a partir de dois documentos: o trabalho coletivo de conclusão de curso da primeira turma de Especialização em Currículo Escolar - um projeto de Ciclo de Formação Humana - datado de 2013, e a proposta de implantação/implementação desse projeto curricular, da segunda turma, de 2016.

Em posse desses documentos, o município busca efetivar uma política de rede a partir da implantação da educação integral e integrada no município, a princípio em três escolas que assumem o título de escolas-piloto para a implantação/implementação da Proposta Curricular por Ciclo de Formação Humana desde o início de 2017. Em 2018, foram mais duas escolas, estas em tempo parcial. Em 2019 três escolas dos anos finais do ensino fundamental ampliaram a política de implantação do CFH. Em 2020, a implantação do CFH ocorreu em todo o segmento da Educação Infantil; em tempo integral em uma escola municipal quilombola; e em tempo parcial em outra escola municipal. Para 2021, pelo planejamento do ano letivo, todas as escolas já terão implantado a Educação Integral e Integrada. 
Nesta forma de organização, a educação acontece pautada na formação integral dos sujeitos, considera suas multirreferências e amplia as possibilidades de aprender por meio da integração com o território e com a sua comunidade. As formas de organização do trabalho pedagógico são modificadas, a autoformação de todos os envolvidos ganha destaque e o protagonismo dos alunos é potencializado.

Como defesa da escola integral, são apresentados no Referencial Curricular por Ciclo de Formação Humana para a Rede Municipal em estudo (2020) as seguintes ideias e posicionamentos:

A partir da década de 90, com a publicação do Estatuto da Criança e do Adolescente - ECA (BRASIL, 1990) e da Lei de Diretrizes e Bases da Educação (BRASIL, 1996), a educação integral se apresenta como possibilidade para minimizar os vários problemas enfrentados pelas crianças e adolescentes em situação de vulnerabilidade e para a melhoria contínua da qualidade da aprendizagem. 0 ECA apresenta o direito à Educação e reitera, no Art. $5^{\circ}$, que: "nenhuma criança ou adolescente será objeto de qualquer forma de negligência, discriminação, exploração, violência, crueldade e opressão [...]" Este artigo apresenta a necessidade de proteção que pode ser viabilizada pela Educação Integral e Integrada ao inserir os estudantes num espaço de inclusão, de valorização de suas singularidades, além de colocá-los em constante interação com educadores comprometidos, na escola ou fora dela e retirá-los da vulnerabilidade social a que estão expostos.

A Lei de Diretrizes e Bases da Educação Nacional, de número 9.394/96, em seu Artigo $\Upsilon^{\circ}$, aponta para o espaço escolar como lugar central do processo educativo, pautado pela relação de ensino e de aprendizagem e coloca a Educação Integral em jornada ampliada, expandindo os limites das práticas educacionais tradicionais, ao dizer que a educação abrange, além dos processos escolares formais, processos formativos na família, convivência, trabalho, instituições de ensino, movimentos sociais e organizações da sociedade civil.

A matriz curricular para o município está organizada por área de conhecimento numa dimensão integral e interdisciplinar. A proposta faz um convite e estimula "novas concepções, discursos e práticas", além de estabelecer como âncoras uma matriz multirreferencial, uma perspectiva intercultural, estruturas por eixos temáticos e a pedagogia de projetos como possibilidade metodológica para efetivação desses eixos.

Esta proposta curricular reorganiza a estrutura curricular do município por Eixos Temáticos. Desta maneira os temas passam a ser o eixo principal e não a disciplina. Fica estabelecida uma estrutura com 04 (quatro) Eixos Temáticos:

a) Ciências Naturais, Matemática e suas Tecnologias; 

b) Ciências Humanas e suas Tecnologias;
c) Linguagens e suas Tecnologias;
d) Estudos Literários.

A Pedagogia de Projetos - a partir de nossas observações e vivências nas escolas de educação integral e Integrada, é possível afirmar que a Pedagogia de Projetos realmente norteia todo o trabalho desenvolvido nos eixos temáticos, uma vez que a cada trimestre é escolhido um tema gerador por meio de assembleia, realizada nas escolas com a representação de todos os agentes que compõem o ambiente: estudantes, gestores, funcionários e professores. Dessa forma, a escolha do tema gerador revela a fluidez presente nos atos pedagógicos proporcionados por esse desenho curricular e permite que todos experimentem o currículo como um processo de construção coletiva, além de enfatizar as múltiplas linguagens e modos de aprender a partir das vivências e experiências de cada um.

Nos ciclos de formação humana, a avaliação se caracteriza como um processo, partindo do princípio que todas as pessoas são capazes de aprender e que as ações educativas, as estratégias de ensino, os conteúdos correspondentes às áreas de conhecimento devem ser planejados a partir das infinitas possibilidades de aprendizagem dos estudantes. A avaliação faz parte do fortalecimento de uma educação humanizadora em que as responsabilidades são compartilhadas e todos os profissionais compreendem a importância de assegurar a permanência do estudante na escola, seu avanço e sucesso nos estudos. A organização do período letivo é definida por trimestre, a avaliação é registrada em conceitos que correspondem ao avanço do estudante para indicar a progressão do mesmo.

Na escola organizada por Ciclos de Formação Humana, a avaliação rompe a lógica classificatória e reconhece os tempos e processos do estudante para, com isso, redirecionar os processos de ensino e de aprendizagem.

A avaliação segue uma organização que contempla a prática do conselho de classe participativo, o acompanhamento mensal através dos registros sistemáticos e de pareceres, e o processo de aprendizagem dos estudantes.

A avaliação é entendida como movimento constante de reflexão sobre a prática pedagógica, reflexão que ganha sentido quando proporciona mudanças na prática do professor, com vistas a realizar intervenções qualitativas no processo de ensino e de aprendizagem.

Desse modo, não há reprovação nas escolas de educação integral e integrada no município referência. 0 Currículo organizado por ciclo de formação humana é uma oportunidade de possibilitar às crianças seu desenvolvimento de acordo com a idade. A criança passa a 
ser o eixo norteador da escola em uma lógica de formação de identidades, de vivência e de cultura, onde, de forma ética, criamos condições para que as identidades se construam pelo desenvolvimento da sensibilidade e pelo reconhecimento do direito à igualdade.

Educar sob a perspectiva da formação humana requer a compreensão das múltiplas inter-relações estabelecidas no cotidiano da escola. Propiciar um ambiente potencializador para que relações horizontais enriqueçam os processos coletivos de construção de conhecimento, além de integrar as múltiplas linguagens e contextos dos que juntos convivem.

A organização escolar baseia-se nos ciclos do desenvolvimento humano ao considerar que o conhecimento está intrinsecamente ligado às fases da vida dos sujeitos e parte do princípio de que estar junto com os seus pares de idade favorece as trocas sociais e formativas, fortalecendo a construção da autoestima, da autoimagem e de identidades. Esta organização está definida conforme Tabela 1:

Tabela 1 - Organização escolar nos ciclos de formação humana

\begin{tabular}{|c|c|c|c|}
\hline Ciclo & $\begin{array}{l}\text { Faixa de Desenvolvimento } \\
\text { (Eixo ou Fase) }\end{array}$ & Idades de Formação & $\begin{array}{c}\text { Agrupamento de Turmas } \\
\text { por Pares de ldade }\end{array}$ \\
\hline \multirow{7}{*}{ I } & \multirow{3}{*}{$1^{a}$ Infância } & \multirow{3}{*}{0 aos 5 anos } & $0 / 3$ anos \\
\hline & & & $3 / 4$ anos \\
\hline & & & $4 / 5$ anos \\
\hline & \multirow{4}{*}{$2^{a}$ Infância } & \multirow{4}{*}{6,7 e $8 / 9$ anos } & $5 / 6$ anos \\
\hline & & & $6 / 7$ anos \\
\hline & & & $7 / 8$ anos \\
\hline & & & $8 / 9$ anos \\
\hline \multirow{3}{*}{$\|$} & \multirow{3}{*}{ Pré-adolescência } & \multirow{3}{*}{9,10 e $1 / 12$ anos } & $9 / 10$ anos \\
\hline & & & $10 / 11$ anos \\
\hline & & & 1 / १ anos \\
\hline \multirow{3}{*}{ |l| } & \multirow{3}{*}{ Adolescência } & \multirow{3}{*}{ १२, ३ e १४ / १५ anos } & १२ / १३ anos \\
\hline & & & $13 / 14$ anos \\
\hline & & & $14 / 15$ anos \\
\hline IV & Juventude/Maturidade & A partir dos 15 anos & A partir dos 15 anos \\
\hline
\end{tabular}

Fonte: Irecê (2020).

A organização do tempo; do espaço; do trabalho da equipe gestora; do trabalho pedagógico dos professores assumem novos significados. Medidas concretas são exigidas na perspectiva de transformar a escola em um espaço propício de aprendizagens. É importante dizer que esse processo, por si só, não poderá garantir às crianças as aprendizagens necessárias, ou seja, as crianças não irão aprender apenas por serem reunidas por idades, 
mas aprendem quando olhamos o sujeito estudante e the possibilitamos a ele vivências significativas para cada fase do seu desenvolvimento biopsicossocial.

Para organizar o trabalho pedagógico, cada turma possui um professorreferência que é o profissional que acompanha o grupo de estudantes para a superação dos desafios de aprendizagem estabelecidos para aquele determinado grupo. Dessa forma, cabe ao professor-referência investigar o processo de construção de conhecimento e de desenvolvimento do estudante a partir das constatações encontradas nessas investigações. Além dos professores-referência da turma, os estudantes também são atendidos por professores-referência dos ambientes de aprendizagem que, como o nome diz, são ambientes que integram as diferentes linguagens e perpassam pelos eixos temáticos. São construídos ambientes de arte, tecnologias, movimento corporal e judô, além de música e xadrez que são componentes curriculares obrigatórios.

A avaliação - o contexto local no qual a escola está inserida também é respeitado na nossa proposta de Educação Integral e Integrada por CFH, como é o caso de uma escola localizada na zona rural do município, e possui ambientes de aprendizagem que respeitem as suas especificidades enquanto escola do/no campo. A conexão com o meio ambiente, com a natureza, a percepção da cidade enquanto agente educativo e formativo é um outro diferencial percebido durante as observações da prática pedagógica das escolas estudadas aqui. A educação extrapola os muros da escola, integra os sujeitos e a comunidade em constante aprendizagem. Assume o sentido pleno de uma educação integrada uma vez que dispõe de um projeto coletivo e minuciosamente elaborado para sua execução.

Tendo em vistas a obtenção de melhorias da qualidade da educação e dos níveis de aprendizagem, a formação docente desponta como um dos temas mais discutidos e relevantes do cenário educacional da atualidade. Para atender aos inúmeros desafios da implantação/implementação da proposta curricular organizada por $\mathrm{CFH}$, a formação docente e da equipe gestora das escolas de educação integral e integrada Irecê assume uma organização diferenciada das demais. Desde o início de 2017 a formação passou a acontecer in loco, os professores dispõem de duas horas semanais, além dos planejamentos, destinadas exclusivamente aos estudos que subsidiam as ações pedagógicas: projetos, programas, concepções de ciclos de formação humana, currículo, dentre as mais diversas temáticas que emergem do cotidiano escolar são abordadas. Mensalmente acontecem momentos de estudos coletivos com as equipes das escolas para ampliação/aprofundamento de estudos demandados pelas equipes de trabalho.

A autoformação docente - um outro aspecto da formação que merece destaque é a autoformação proporcionada pela escrita de memoriais formativos. Esse registro contempla dois eixos: o Eu estudante e o Eu professor na escola de educação integral e integrada. No primeiro eixo, discorre sobre quem é no mundo, na família, como se constituiu. Já no segundo, 
pensa sua prática ao narrar, com pretensões de radicalidade, como acontecem as atividades que consideraram potencializadoras de aprendizagem durante todo o ano letivo, além de registrar com imagens, fotografias e relatos de estudantes e da comunidade como um todo. A construção desse memorial é realizada tanto pela equipe gestora quanto pelos docentes das escolas, e é orientado e avaliado pela coordenação técnica das escolas de educação integral e integrada do município.

Percepções de quem faz o currículo - grandes são os desafios colocados à tarefa contemporânea de ensinar. Para a implantação/implementação da proposta curricular por CFH é imprescindivel conhecer os processos de ensinar; aprender a refletir sobre suas práticas; aprender a importância do trabalho coletivo; compreender que não existe uma prática neutra e que o compromisso político é necessário para que seja possível vislumbrar uma educação com qualidade. Como dito, o propósito do trabalho pedagógico é deslanchar um trabalho de autogestão da ação pedagógica nas escolas da Rede, como política de desenvolvimento da educação municipal e efetivação da proposta curricular no ciclo de formação humana.

No momento da escrita desta descrição já é possivel elencar algumas atualizações que, de um modo ou de outro, podem ser consideradas exitosas. Destacamos, a priori, a autoformação não só docente, mas de todos os agentes das escolas de educação integral e integrada que vem se permitindo ousar, criar e reescrever a história da educação municipal. A melhoria dos índices de avaliadores externos também é outro ponto de relevância. Uma das escolas municipais que adotaram o programa pontuou a primeira nota 6,0 no IDEB (ĺndice de Desenvolvimento da Educação Básica). As escolas se perceberam num movimento de contínua integração de saberes, vivências e experimentos que tornam o cotidiano escolar ainda mais pulsante.

0 diálogo com o entorno das escolas e com a cidade é potencializado por esta organização curricular que possibilita ricas trocas e ampliação de mundo. A relação das crianças com a família, o bairro, o meio, as associações, entidades filantrópicas, o comércio local é redimensionado. A redução dos índices de evasão e a credibilidade das escolas também são visíveis. As famílias também se integram a esse cenário e aprendem juntas com as escolas na busca por compreender novos conceitos, novas formas de organização do trabalho pedagógico, de avaliação e de participação e de atividades diferenciadas.

Outro ponto relevante em nossa análise diz respeito ao protagonismo presente em todas as escolas. Experiências como a construção de robôs por meio de aulas de robótica no ambiente de tecnologias é algo nunca antes visto em nossa Rede. As crianças produzem material para a exploração investigativa e uma estudante com deficiência visual lançou um livro no Encontro Literário realizado no município em 2018. A arte neste novo arranjo possibilita criações belíssimas. 


\title{
3.2 O PROJETO IRECÊ: A LONGA E POTENTE PARCERIA MUNICÍPIO/UNIUERSIDADE
}

Irecê é um município que possui cerca de oitenta mil habitantes, localizado no nordeste brasileiro, tem como principal referência do percurso histórico de formação dos profissionais da educação, a parceria firmada com uma universidade federal. A partir desta parceria, a cidade ofereceu Licenciatura em Pedagogia, Especialização em Currículo Escolar e Mestrado Profissional em Educação aos professores do município que construíram, em 2013, o Projeto Curricular por Ciclo de Formação Humana, que é o trabalho de conclusão de curso da primeira turma de Especialização em Currículo Escolar. Em 2016, a segunda turma construiu, no seu TCC coletivo, a proposta de implantação/implementação do projeto curricular. Contase também com os chamados Projetos de Intervenção do Mestrado Profissional.

Tudo começou nos idos de 2001 quando o município procurou a direção da universidade. Naquele momento, estava na direção o Prof. Nelson Pretto que encampou a demanda. Formulou-se o projeto deste Programa de Formação de Professores, anunciando:

\begin{abstract}
Este programa visa a integrar em rede, tecnológica ou não, diferentes projetos que irão incrementar o processo de formação dos professores, disponibilizando-thes uma estrutura pedagógica comunicacional e administrativa interativa e flexível. Pretende, ainda, se constituir num processo de intervenção profunda e coletiva, nas práticas cotidianas desses professores no interior de cada escola, em cada comunidade circunvizinha à escola e no município como um todo, ao tempo em que promove a formação em nivel superior dos professores em exercício da Rede Municipal de Ensino do Município. (IRECÊ, 2003).
\end{abstract}

Um amplo e ousado objetivo/compromisso que ao longo dos anos foi se concretizando. São projetos pensados inicialmente quando da elaboração do Projeto do Programa (2002-2003) ou surgido de demandas que foram emergindo como ressonância da presença marcante no município que efetivamente concretiza a muito conclamada e pouco executada indissociabilidade ensino/pesquisa/extensão: Tabuleiros Digitais (Internet pública); Ponto de Cultura (do Ministério da Cultura); teses; dissertações e monografias que têm como campo de investigação o Programa; elaboração do currículo EJA; curso de formação para professores de toda a microrregião; Projeto Biblioteca são alguns exemplos.

0 fator deflagrador desta parceria foi a demanda por formação de professores incentivada e/ou imposta pelo disposto no Art. 62 da Lei de Diretrizes e Bases da Educação 
Nacional (Lei 9.394/96), que visa a conferir ao conjunto de professores da educação básica do país, como patamar mínimo de escolaridade, o nível superior.

Uma parceria que se inicia com um dilema posto: o entendimento da justeza e da urgência da lei que dispunha sobre a formação universitária a todos os professores brasileiros eclipsados pelo receio que tal dispositivo levasse a mudanças apenas tutoriais, ou seja, cursos que podem ser adjetivados como aligeirados e que criam os cenários de "diploma na mão sem a respectiva formação".

Foi, pois, com alertas a este dilema que foi criado o Curso de Licenciatura em Pedagogia - ensino fundamental/séries iniciais oferecido aos professores efetivos, dirigentes e coordenadores que atuam na Rede Municipal de ensino local. Aconteceram duas turmas: 2004-2006 e 2008-2010.

Um curso em caráter experimental com currículo organizado com o respaldo da Resolução 02/2000 do CONSEPE, que faculta em seu Art. $8^{\circ}$. $§ 5^{\circ}$., a composição de atividades curriculares. Um fluxograma não-disciplinar, flexível e abrangente que possibilitou um curso com êxitos marcantes e que vem contribuindo muito com a pesquisa do campo curricular.

As teorizações engendraram os seguintes objetivos:

- Possibilitar percursos, de formação docente, pautados na produção individual e coletiva de conhecimento e em propostas de ação pedagógica, e a compreensão sobre a complexa relação entre pessoas, máquinas, natureza e grupos sociais e essa relação nos processos de ensinar e aprender.

- Articular a formação de uma postura crítica, diante das mudanças do mundo contemporâneo com umas práxis educativas dinâmica, ativa e propositiva.

- Promover a compreensão das múltiplas linguagens que constituem o desenvolvimento dos sujeitos em constante processo de formação, evidenciando a dimensão lúdica como possibilitadora do desenvolvimento de um processo de ensino e de aprendizagem mais criativo, relacional, articulador.

- Desenvolver atitudes favoráveis diante do uso de tecnologias na educação, como elementos estruturantes de diferentes possibilidades de formação dos cidadãos do mundo contemporâneo, praticando o processo de ensino e de aprendizagem voltado para a busca, análise e tratamento de informações.

- Estimular o conhecimento e o espírito de pertencimento em relação aos valores locais de cultura, sejam eles tradicionais ou contemporâneos, instalando um processo permanente de produção e disseminação dos valores culturais da região e sua incorporação nos processos pedagógicos escolares, com especial atenção para as questões do ambiente natural e artificial, a partir da visibilidade e discussão pública dos processos de produção cultural da região. (IRECÊ, 2003). 
Processos horizontais, Processos coletivos, Centros instáveis, Currículo hipertextual, Participação efetiva, Formação permanente e continuada, Cooperação, Simultaneidade entre a escrita e a oralidade, Sincronicidade na aprendizagem são princípios postulados no projeto do Programa que se desdobram na pauta das escolhas metodológicas em autonomia e pluralidade.

No primeiro semestre de 2009, uma outra demanda levou à formulação de mais um projeto do Programa: uma pós-graduação lato sensu, a Especialização em Currículo Escolar.

Esta especialização foi um clamor dos egressos da primeira turma e da graduação o projeto elaborado - em consonância com a dinâmica em rede que vinha sendo construída, desde 2001 - propôs um currículo que abarcou outra demanda: a da (re) formulação do currículo da Rede de Ensino Municipal.

Além do desenho curricular baseado no curso de pedagogia, destaca-se que no seu processo metodológico houve a participação da segunda turma do curso de licenciatura em pedagogia, e dos professores e gestores da Rede de Ensino não estudantes da pósgraduação e o TCC coletivo que, como já citado, elaborou projetos de currículo para diversos municípios.

0 passo seguinte foi o Mestrado Profissional em Educação - currículo, linguagens e inovações pedagógicas. Após duas turmas, sendo que a segunda já atingiu além de Irecê outros municípios do território, segue como curso regular da Faculdade de Educação.

\subsection{O GRUPO DE PESQUISA}

Neste ínterim, o projeto se torna, pelo seu cotidiano, um grupo de pesquisa. Em 2006, foi oficializado como grupo do CNPQ, com a seguinte pergunta-mestre:

Quanto à formação em exercício de professores, quais concepções e ações possibilitarão a construção de currículos contemporâneos que ampliem a esfera de existência do ser de cada professor com ressonâncias nas suas práticas pedagógicas e não apenas thes confira um diploma universitário?

\subsection{A PESQUISA}

Com as teses, dissertações e monografias que têm como campo de investigação o Programa, criou-se a metodologia denominada: Investigação em Campo-Piloto, um tipo de 
pesquisa que demanda a criação de seu próprio campo. Campo este que, concomitantemente, é campo de teste de teorias pré-estabelecidas e alimentador de novas construções teóricas. Portanto, a implantação da Escola de Educação Integral e Integrada, mesmo fora do âmbito oficial do projeto, continua um campo-piloto para potentes investigações.

A Investigação em Campo-Piloto é um tipo de pesquisa que tem como intenção contemplar a concomitância entre teoria e prática, que pode ser assim entendida: as teorias são criadas a partir de movimentos dialógicos com a realidade (primeiro movimento) e, ao serem colocadas em contato com o mundo, recriam, a partir de seus pontos de vista, essa própria configuração estudada (segundo movimento), que, por sua vez, propiciará novos processos de investigação que farão surgir novas teorias, em um constante movimento de atualização, não necessariamente progressivo (terceiro movimento).

0 campo-piloto de investigação vem se constituindo em experimentos - de ideias teorizadas pelo Núcleo de Pesquisa - pelos quais se tem a oportunidade de exercitar práticas pedagógicas outras. Na licenciatura, eco à discussão contemporânea sobre curriculos outros e formação de professores, o currículo do curso é construído ao longo da realização do mesmo, integrando em rede, preferencialmente tecnológica, o processo de formação dos professores, e disponibilizando aos professores uma estrutura interativa e flexível nas esferas pedagógica, comunicacional e administrativa, com ressonâncias nas práticas pedagógicas de cada um deles, e incentivando e promovendo ações que ultrapassem a esfera da Rede Municipal de Ensino. Trabalhamos com o conceito de Campo das possibilidades pensadas (condição instituída) como desencadeador do Campo das atualizações (condição instituinte).

\section{CONFLITO MUNDO/TERRA: OS DILEMAS POSTOS E O PENSAR UM CENÁRIO PROSPECTIUO}

Dar um zoom na Rede, hoje, é ver uma "orquestra" de violinos tocados por estudantes para receber os professores na Jornada Pedagógica quando há, também, uma crença absoluta nas avaliações externas; é ver, mesmo que pontualmente, a política de coronéis ainda viva. É ler nas redes sociais: "Obrigado pelo carinho! Uma pequena revolução acontece no semiárido brasileiro" na página virtual de um professor de outro estado do país após participar de evento educacional em Irecê. E considerar cotidianamente que pouco tem sido feito.

São muitos os dilemas postos e os encaramos não necessariamente no sentido de dilema como "premissa dupla", mas no sentido mais próximo do conflito, como "raciocínios insolúveis ou conversíveis", como nos mostra Abbagnano (1982) em seu Dicionário de Filosofia. Operar com este sentido de dilema não é tarefa fácil, pois é da natureza humana o desejo, 
sempre potente, de resolver problemas, se livrar das tensões, se completar em nossa finitude. Uma natureza que, Força Ativa, estabelece e tenta manter o que seria pretensamente a ordem natural do Universo e/ou primeva de cada universo e esta força não está ausente da Rede de Educação de Irecê. Estar no dia a dia escolar, viver a carência cotidiana do município reativa essa natureza humana que busca soluções.

A solução não estaria na descoberta da impossibilidade da solução ou, ao menos, na descoberta da provisoriedade das soluções? $E$ quem nos ajuda a pensar sobre as "respostas" aos dilemas é Derrida em A farmácia de Platão, escrita em 1972, com um exemplo interessante - o deus egípcio Thoth e o rei do Egito discutem a necessidade de alfabetizar os súditos - a nos mostrar que muitas vezes a lógica da argumentação se desfaz e não se tem uma disputa para se descobrir a verdade, mas, sim, a "ambiguidade da diferença". Dada a indecidibilidade do dilema, a questão não é quem está certo, mas que decisão tomar. Diríamos que indecidibilidade, este significante emprestado da informática, que indica a não existência de uma resposta sim ou não para um algoritmo, pode ser uma marca potente para a compreensão do cenário educativo de Irecê e seus dilemas postos.

No primeiro documento do Projeto Irecê, havia uma provocação via Derrida lapud IRERÊ, 2003):

\footnotetext{
Cuidado com os abismos e as gargantas, mas cuidado também com as pontes e as "barriers". Cuidado com que abre a universidade para o exterior e para o sem-fundo, mas cuidado também com o que, fechando-a em si mesma, não criaria senão um fantasma de cercado, a colocaria à mercê de qualquer interesse ou a tornaria perfeitamente inútil. Cuidado com as finalidades, mas o que seria uma universidade sem finalidades?
}

A ambiguidade da diferença, já antevista virtualmente com esta primeira colocação dilemática, se mostra vivamente, em um dos primeiros aprendizados do pessoal da universidade litorânea que chega ao semiárido, no já citado tempo bom é quando chove! que interpretamos como uma reiteração ao não-essencialismo.

E a implantação da Escola de Educação Integral e Integrada, nos impõe os seguintes não tão novos dilemas:

a) quais traduções, hibridações, deslocamentos emergiram no instituído cotidiano?

b) na agenda pedagógica do território, quais disputas discursivas se impuseram? 
c) o que do espírito iluminista que ronda as diversas abordagens sobre a escola, em nível nacional, se impôs individual e/ou coletivamente?

d) como não ser teleológico frente as tão prementes demandas?

e) como ficam as relações políticas partidárias frente a necessidade da visibilidade do que é realizado?

Frente a indicibilidade, perguntas não respondíveis. Apenas vestígios aqui e acolá, onde o mundo planta $X$, a terra, muitas vezes, colhe $Y$. As demandas por fortalecimento da Educação ocultando as defesas de fundamentos fracos, o orgulho de uma educação humanizadora olvidando a descentralização do sujeito, a justa vontade de "assegurar" quando os riscos contingenciais são evidentes. Ou não! Diria o poeta.

Voltemos a Deleuze, ou melhor ao nosso roubo criativo de sua ideia de que não existe obra de arte que não faça apelo a um povo que ainda não existe (DELEUZE, 1999, p. 14). Se currículo, como resistência artística, é apelo a um povo que ainda não existe, nos falta ainda uma narrativa, a do Cenário Prospectivo.

A teoria da Incerteza ao interpretar o mundo como evento, e não como palco estanque onde são colocados os desejos um a um, inspira o que se convencionou chamar Cenários Prospectivos, que são cenários pensados como exercício de prováveis rupturas, pois as trajetórias são destruídas seja qual for a precisão da descrição. 0 que se apresenta é um mundo de possibilidades (INSTITUTO DE PESQUISA ECONÔMICA APLICADA, 2017).

É um exercício do futuro em meio ao não controle e às contingências, se tornando o nosso presente. Para narrar o nosso cenário prospectivo, se faz premente a introdução de um novo elemento, a BNCC - Base Nacional Comum Curricular (BRASIL, 2018).

Frente à BNCC, uma normatização que estabelece um "currículo único" ao país, mesmo que permitindo uma parte diversificada - um questionamento se impõe: como será o enfrentamento possível em territórios que, como o de lrecê, tem os cenários educativos provocados por cosmovisões não finalistas e descentralizantes que defendem que as coisas acontecem no a-com-tecer?

Hoje, o nosso exercício de cenário prospectivo é um exercício de enfrentamento. Seguem-se as nossas possiveis respostas:

a) pondera-se que a aceitação da contingência, do risco, da provisoriedade, enfim, a emergência acontecimental encarada como parte compulsória da vida e, não, como condição a ser combatida em nome do sucesso curricular, 
como ocorre, hegemonicamente, nas propostas curriculares centralizadas, torna este cenário potencial traidor da natureza da BNCC;

b) sempre lembrar que como outro qualquer documento de programas e políticas públicas estilo barthesniano, uma desejada trapaça.

A primeira experiência, Jornada Pedagógica de 2020, sob a égide da BNCC, foi o exercício de encará-la, menos com uma Base e mais como uma referência, assim como de encontrar as possibilidades de uma maior adaptação da BNCC ao nosso currículo e menos a adaptação de nosso currículo à Base.

Um cenário prospectivo é engendrado no e pelo conflito mundo/terra e, ao seu tempo, criador de conflitos mundo/terra outros.

\section{CONSIDERAÇÕES FINAIS}

Este artigo desenhou cenários - cenários mundo, cenários Terra - engendrados nos espaços educacionais do município de Irecê. Pretendeu ser uma radical leitura dos mais variados textos que se apresentam sobre e em cada cenário e seus jogos discursivos e, quiçá, possibilitar leituras outras com uma radicalidade que enseje cenários outros.

\section{REFERÊNCIAS}

ABBAGNANO, N. Dicionário de Filosofia. Tradução: Alfredo Bosi. São Paulo: Mestre Jou, 1982.

BARTHES, R. A aula: aula inaugural da cadeira de Semiologia literária do colégio de França; pronunciada dia 7 de janeiro de 1977. 14. ed. São Paulo: Cultrix, 2007.

BRASIL. Lei n. 8.069, de 13 de julho de 1990. Dispõe sobre o Estatuto da Criança e do Adolescente e dá outras providências. Diário Oficial da União, Brasília, DF, 16 jul. 1990. Disponivel em: http://www.planalto. gov.br/ccivil_03/LEIS/L8069.htm\#art266. Acesso em: 17 maio 2019.

BRASIL. Lei n. 9.394, de 20 de dezembro de 1996. Estabelece as diretrizes e bases da educação nacional. Diário Oficial da União, Brasília, DF, 23 dez. 1996. Disponivel em: http://www.planalto.gov.br/ ccivil_03/Leis/L9394.htm. Acesso em: 17 maio 2019.

BRASIL. Ministério da Educação. Base Nacional Comum Curricular. Brasilia, DF: MEC, 2018. Disponível em: http://basenacionalcomum.mec.gov.br/images/BNCC_El_EF_1105१8_versaofinal_site.pdf. Acesso em: 10 ago. 2019. 
CARVALHO, M. I. 0 a-com-tecer de uma formação. Revista da FAEEBA - Educação e Contemporaneidade, Salvador, v. 17, n. 29, p. 159-168, jan./jun. 2008.

CARVALHO, M. I. A escola fraca da segunda ruptura curricular - um estudo sobre o a-com-tecer de currículos do Brasil e de Portugal. 2016. Relatório (Pós-doutorado) - Faculdade de Educação, Universidade Federal da Bahia. 2016

CARVALHO, M. l.; MOREIRA, A. P. 0 A-Com-Tecer do FEP Contado em Drops. In: PIMENTEL JUNIOR, C.; SALES, M. A.; JESUS, R. M. V. (org.). Currículo e Formação de Professores: redes acadêmicas em (des) articulação. Campinas: Pontes Editores, 2018. p. 45-65.

DELEUZE, G. 0 ato de criação. Folha de S. Paulo, São Paulo, p. 2-15, 27 jun. 1999. Caderno Mais.

DERRIDA, J. A farmácia de Platão. São Paulo: Luminuras, 2005.

DERRIDA, J. 0 olho da universidade. São Paulo: Estação Liberdade, 1999

FEYERABEND, P. Contra o método. Rio de Janeiro: Francisco Alves, 1989.

FOUCAULT, M. Questions on Geography. In: FOUCAULT, M. Power/Knowledge: selected interviews and other writings 1972-1977. New York: Pantheon Books, 1980.

GABRIEL, C. T. Conhecimento escolar e emancipação: uma leitura pós-funcional. Cadernos de Pesquisa Fundação Carlos Chagas, São Paulo: Fundação Carlos Chagas, n. 159, mar. 2016.

GRUPO FEP. Formas FEPEANAS de produzir conhecimento significação. In: REUNIĨ̃ DA ANPED, 39., 2019, Niterói. Anais [...] Niterói, 2019.

HEIDEGGER, M. A origem da obra de arte. Rio de Janeiro: Faculdade de Letras/UFRJ, 2006

INSTITUTO DE PESQUISA ECONÔMICA APLICADA. Associação Nacional dos Servidores da Carreira de Planejamento e Orçamento (BRASIL). BRASIL 2035: cenários para o desenvolvimento. Brasília: Ipea: Assecor, 2017. Disponivel em: https://www.ipea.gov.br/portal/images/stories/PDFs/livros/livros/170606_ brasil_2035_cenarios_para_desenvolvimento.PDF. Acesso em: 17 maio 2019.

IRECÊ. Programa de Formação continuada para o Município de Irecê. Irecê: [s. n.], 2003. Disponível em: http://www.irece.faced.ufba.br/twiki/bin/view/UFBAlrece/WebPrograma. Acesso em: 17 maio 2019.

IRECÊ. Referencial Curricular por Ciclo de Formação Humana para a Rede Municipal de Educação de Irecê. Irecê: [s. n.], 2020.

JESUS, R. M. V. de. Comunicação da experiência filmica e experiência pedagógica da comunicação. 2012. Tese (Doutorado em Educação) - Faculdade de Educação, Universidade Federal da Bahia, Salvador, 2012. 
LÉVY, P. 0 que é o virtual? São Paulo: Ed. 34, 1996. (Coleção trans).

LOPES, A. C. Teorias Pós-Criticas, Política e Currículo. Revista Educação, Sociedade e Culturas, Porto, n. 39, p. 7-23, 2013. Disponivel em: https://www.fpce.up.pt/ciie/sites/default/files/02.AliceLopes.pdf. Acesso em: 10 ago. 2019.

MACEDO, E. A noção de crise e a legitimação de discursos curriculares. Currículo sem Fronteiras, v. 13, n. 3, p. 436-450, 2013. Disponivel em: http://www.curriculosemfronteiras.org/vol13iss3articles/emacedo.pdf. Acesso em: 17 maio 2019.

MERREL, F. Simplicity and complexity - pondering literature, science, and painting. Michigan: The University of Michigan Press, 1997.

PIERRE E. A. St. Uma história breve e pessoal da pesquisa pós-qualitativa: em direção à "pós-investigação". Práxis Educativa, Ponta Grossa, v. 13, n. 3, p. 1044-1064, set./dez. 2018. Disponivel em: http:// www.revistas2.uepg.br/index.php/praxiseducativa. Acesso em: 17 maio 2019.

PRIGOGINE, I. 0 fim das certezas: tempo, caos e as leis da natureza. São Paulo: Ed. Unesp, 1996.

SANTOS, M. A natureza do espaço: técnica e tempo razão e emoção. São Paulo: Hucitec, 1996.

SOUZA, E. M. de F. Pontos para uma Teoria do Currículo em Educação de Jovens e Adultos. Tese (Doutorado em Educação) - Faculdade de Educação, Universidade Federal da Bahia, Salvador, 2003. Disponivel em: https://repositorio.ufba.br/ri/bitstream/ri/15598/1/ESTER\%20M\%20F\%20SOUZA\%20 tese\%20completa.pdf. Acesso em: 15 maio 2019.

VATTIMO, G. 0 fim da modernidade. 2. ed. São Paulo: Martins Fontes, 2007.

ŽIŽEK, S. Acontecimento: uma viagem filosófica através de um conceito. Tradução: Carlos Alberto Medeiros. Rio de Janeiro: Zahar, 2017.

Endereço para correspondência: Rua Juruna, 372, Cond. Aldeia Jaguaribe, Patamares, 41680-220, Salvador, Bahia, Brasil; misc@ufba.br 